\title{
Pengaruh Pijat Punggung terhadap Adaptasi Nyeri Persalinan Fase Aktif Lama Kala II dan Perdarahan Persalinan pada Primigravida
}

\author{
The Influence of Back Massage toward the Decrease of Labor Pain in \\ Active Phase Length of Stage II and Labor Bleeding in Primigravida
}

\author{
Wiwin Renny Rahmawati, Siti Arifah, Anita Widiastuti
}

\section{Program Studi Keperawatan Politeknik Kesehatan Kementerian Kesehatan Semarang}

\begin{abstract}
Abstrak
Rasa nyeri persalinan yang tinggi dapat menimbulkan kecemasan pada ibu, terutama pada ibu primigravida. Nyeri yang tidak bisa diadaptasi oleh ibu yang akan melahirkan dapat meningkatkan perasaan cemas pada ibu, rasa cemas tersebut dapat menyebabkan terjadinya persalinan yang lama, sehingga kekuatan ibu akan habis saat persalinan yang berakibat terhadap kejadian perdarahan serta kala II lama. Tujuan penelitian ini untuk mengetahui pengaruh pijat terhadap pengurangan rasa nyeri persalinan fase aktif, lama kala II, dan perdarahan persalinan pada primigravida di Puskesmas Magelang Selatan. Penelitian ini merupakan penelitian desain kuasi eksperimental bentuk perbandingan kelompok statistik, yaitu memberikan perlakuan atau intervensi, kemudian dilakukan pengukuran atau observasi. Hasil pengukuran pada kelompok perlakuan dibandingkan dengan kontrol. Skala rasio digunakan. Subjek penelitian sebanyak 40 orang. Analisis data dengan uji Mann Whitney didapatkan hasil ada pengaruh pijat punggung terhadap adaptasi rasa nyeri persalinan fase aktif, lama persalinan kala II dan perdarahan persalinan pada primigravida dengan nilai $p=$ 0,001 .
\end{abstract}

Kata kunci: Nyeri persalinan, pijat punggung, primigravida

\footnotetext{
Abstract

Severe labour pain can cause anxiety especially in primigravida. Many mothers who experience labour have not got action yet to minimize labour pain, If labour pain cannot be decreased, it will cause mother anxiety, that anxiety result in long labour, so energy will decrease that can cause labour bleeding. Therefore it is needed to take action to minimize labour pain. One of that action was back massage that could stimulate endorphine, so the pain will decrease. The objectives of this study was to know the influence of massage towards the decrease of labour pain in active fase, lenght of stage II, and labour bleeding in primigravida at Publich Health Center Magelang Selatan. Quasi-experimental design was applied with static group comparation. The design gave intervention, then measurement and obser-
}

vation was conducted. The intervention group result was compared to control. Ratio scale was used. Subject of this research was 40 person. After analizing data by man Whitney test, here are the influence of back massage toward the decrease of pain labour in active fase, lenght of labour kala II and labour bleeding in primigravida with $p$ value $=0.001$.

Keywords: Labour pain, back massage, primigravida

\section{Pendahuluan}

Persalinan merupakan proses membuka dan menipisnya serviks sehingga janin turun ke dalam jalan lahir. ${ }^{1}$ Kejadian itu terjadi seiring dengan otot-otot rahim yang berkontraksi. Pada saat terjadi kontraksi di rahim, kepala janin bergerak melewati jalan lahir yang menyebabkan tekanan pada kandung kemih, rektum, tulang belakang dan tulang pubik yang juga menyebabkan terjadinya rasa nyeri pada ibu. ${ }^{2}$

Nyeri persalinan dapat memengaruhi kontraksi uterus melalui sekresi kadar katekolamia dan kortisol yang menaikkan aktivitas sistem saraf simpatis, perubahan tekanan darah, denyut jantung, pernapasan dan akibatnya memengaruhi lama persalinan. Nyeri juga dapat menyebabkan aktivitas uterus yang tidak terkoordinasi yang akan mengakibatkan persalinan lama. Adapun nyeri persalinan yang berat dan lama dapat memengaruhi verifikasi sirkulasi maupun metabolisme yang harus segera diatasi karena dapat menyebabkan kematian. ${ }^{3}$ Rasa nyeri persalinan yang tinggi dapat menimbulkan kecemasan pada ibu, terutama pada ibu primigravida. Saat ini masih

Alamat Korespondensi: Wiwin Renny Rahmawati, Program Studi

Keperawatan Poltekkes Kemenkes Semarang, Jl. Perintis Kemerdekaan Kotak Pos 221 Magelang 11440, Hp.081328454135, e-mail: wiwinrr@yahoo.co.id 
banyak ibu primigravida yang saat persalinan belum mendapat tindakan untuk mengurangi nyeri, padahal bila nyeri saat persalinan tidak berkurang dapat meningkatkan perasaan cemas. Rasa cemas tersebut dapat menyebabkan terjadinya persalinan yang lama sehingga kekuatan (tenaga untuk mengejan) ibu akan habis saat persalinan tersebut. Suatu tindakan yang tidak menimbulkan efek samping pada ibu dan bayi diperlukan untuk mengurangi nyeri persalinan tersebut. Tindakan tersebut antara lain dengan pijat punggung, yang dapat merangsang saraf endorfin sehingga rasa nyeri dapat berkurang.

Rasa nyeri pada persalinan dalam hal ini adalah nyeri kontraksi uterus yang dapat mengakibatkan peningkatan aktivitas sistem saraf simpatis, perubahan tekanan darah, denyut jantung, pernapasan dengan warna kulit dan apabila tidak segera ditangani akan meningkatkan rasa khawatir, tegang, takut, dan stres. ${ }^{4}$ Nyeri persalinan dapat memengaruhi kontraksi uterus melalui sekresi kadar katekolamin dan kortisol yang dapat memengaruhi durasi persalinan. Nyeri juga dapat menyebabkan aktivitas uterus yang tidak terkoordinasi dan akan mengakibatkan persalinan lama. Adapun nyeri persalinan yang berat dan lama dapat memengaruhi verifikasi sirkulasi maupun metabolisme yang harus segera ditangani karena dapat menyebabkan kematian janin. ${ }^{3}$

Banyak permasalahan yang bisa terjadi akibat nyeri persalinan yang tidak diatur dengan baik. Perdarahan persalinan juga bisa mengikuti persalinan dengan nyeri yang tidak bisa diadaptasi. Hal ini dapat terjadi pada persalinan dengan kala II lama yang bisa menyebabkan kondisi rahim yang terlalu lemah. Tindakan-tindakan untuk menurunkan nyeri secara medis (menggunakan obat) hampir semua mempunyai efek samping pada ibu dan juga pada janin. Sedangkan, tindakan nonmedis antara lain relaksasi, teknik pemusatan pikiran dan imajinasi, teknik pernapasan, hidroterapi, pijat atau sentuhan terapeutik, hipnosis, akupunktur dan akupresur, dan lain-lain yang sebagian besar bersifat distraksi yang dapat menghambat otak untuk mengeluarkan sensasi nyeri serta tidak menyebabkan efek samping pada ibu dan juga bayi. Peneliti melakukan penelitian ini untuk mengetahui pengaruh pijat punggung terhadap adaptasi nyeri persalinan fase aktif, lama kala II, dan perdarahan persalinan pada primigravida.

\section{Metode}

Penelitian ini menggunakan desain studi kuasi eksperimental bentuk perbandingan kelompok statistik, yaitu memberikan perlakuan atau intervensi kemudian dilakukan pengukuran atau observasi. Subjek penelitian adalah semua ibu primigravida yang bersalin pada fase aktif di Puskesmas Magelang Selatan pada bulan Juni sampai dengan Agustus 2013. Populasi adalah keseluruhan dari subjek penelitian. ${ }^{5}$ Populasi adalah wilayah generalisasi yang terdiri atas objek/subjek yang mempunyai kualitas dan karakteristik tertentu yang ditetapkan oleh peneliti untuk dipelajari dan kemudian ditarik kesimpulannya. ${ }^{6}$ Populasi dalam penelitian ini adalah adalah ibu bersalin pada primigravida fase aktif di Puskesmas Magelang Selatan bulan Juni hingga Agustus 2013. Sampel adalah sebagian atau wakil populasi yang diteliti. ${ }^{5}$ Sampel adalah bagian dari jumlah dan karakteristik yang dimiliki oleh populasi. ${ }^{7}$ Pengambilan sampel dalam penelitian ini dengan menggunakan total sampel. Sampel yang diambil adalah ibu primigravida kala I fase aktif persalinan fisiologis yang bersalin di Puskesmas Magelang Selatan bulan Juni hingga Agustus 2013. Sampel yang digunakan adalah pasien yang memenuhi kriteria inklusi dan eksklusi yang bersedia mengikuti persalinan dengan teknik pijat. Kriteria eksklusi pada penelitian adalah responden yang mendapatkan program oksitosin drip dan responden mengalami kegawatan pada fase aktif.

Penelitian ini menggunakan data primer yang diperoleh langsung dari subjek penelitian sebagai sumber informasi dengan menggunakan alat pengukuran atau alat pengambilan data. Data sekunder adalah data yang diperoleh dari orang lain atau tempat lain dan bukan dilakukan oleh peneliti sendiri. ${ }^{4}$ Data yang digunakan pada penelitian ini berupa data primer dan data sekunder. Data primer diperoleh dengan cara mengisi lembar observasi respons atau reaksi klien terhadap nyeri pada klien yang dilakukan pijat punggung dan yang menggunakan teknik napas dalam. Data sekunder diperoleh dari catatan persalinan ibu primigravida inpartu kala I dan status kesehatan ibu primigravida inpartu kala I responden di Puskesmas Magelang Selatan. Sebelum dilakukan penelitian, responden diberikan penjelasan perihal penelitian yang akan dilakukan serta persetujuan untuk menjadi responden. Perlakuan yang diberikan berupa pijat punggung dengan menggunakan kedua telapak tangan untuk menekan kedua sisi punggung. Pijatan dilakukan dengan seluruh bagian telapak tangan dan jemari harus menyentuh tubuh sehingga terasa ketegangan. Pijatan kuat dengan gerakan melingkar dilakukan di pangkal tulang belakang mengunakan tangan atau ibu jari di sekitar cekungan pantat. Pijatan memerlukan tekanan yang kuat untuk melawan kontraksi yang kuat di daerah itu. Proses pemijatan ini dilakukan sekitar 3 - 10 menit. Setelah itu, observasi juga dilakukan. ${ }^{8}$

Instrumen penelitian adalah alat-alat yang akan digunakan untuk pengumpulan data. ${ }^{9}$ Oleh karena itu, untuk mempermudah peneliti dalam proses pengumpulan data digunakan lembar observasi yang berupa respons atau reaksi klien dan dengan menggunakan skala nyeri bourbonnais berdasarkan penilaian objektif. Peneliti tidak menggunakan uji validitas dan uji relibialitas karena skala yang digunakan sudah menjadi patokan dan 
ukuran standar sehingga tidak mungkin untuk mengubahnya. Analisis univariat dilakukan untuk menghasilkan distribusi frekuensi dan persentase tingkat skala nyeri dan lama kala II dan jumlah perdarahan persalinan. Analisis bivariat yang dilakukan terhadap dua variabel untuk mencari pengaruh variabel independen (pijat punggung) dengan variabel dependen(nyeri persalinan, lama kala II, dan perdarahan persalinan). Uji statistik yang digunakan adalah uji t untuk sampel tidak berpasangan.

\section{Hasil}

Responden penelitian berjumlah 40 orang. Karakteristik responden penelitian pada variabel usia dapat peneliti laporkan. Kelompok yang mendapat perlakuan pijat punggung memiliki usia rata-rata 24,05 tahun dengan usia termuda 16 tahun dan usia tertua 31 tahun. Kelompok kontrol yang memiliki rata-rata 24,95 tahun dengan usia termuda 19 tahun dan usia tertua 31 tahun. Meskipun usia berpengaruh terhadap persalinan, peneliti sudah berupaya untuk menjadikan responden homogen pada variabel ini untuk meminimalkan bias pada hasil penelitian. Masa reproduksi merupakan masa yang terpenting bagi wanita dan berlangsung kira-kira 33 tahun. Haid pada masa ini paling teratur dan siklus pada alat genetalia bermakna untuk memungkinkan kehamilan. Ovulasi terjadi sekitar 450 kali, dan wanita mengalami perdarahan selama 1.800 hari.

Gambar 1 menunjukkan bahwa semua responden yang mendapatkan perlakuan pijat punggung, pada kala I menyatakan bahwa nyeri yang mereka rasakan berkisar pada rentang nyeri sedang. Sedangkan, pada kelompok kontrol masih terdapat $30 \%$ responden yang merasakan nyeri berat pada fase aktif.

Berdasarkan sajian data dapat diketahui bahwa 90\% responden yang mendapat perlakuan pijat punggung bisa melahirkan bayi pada 30 menit pertama setelah dinyatakan pembukaan lengkap. Pada kelompok kontrol, hanya 40 persen yang melahirkan pada kala II 30 menit pertama. Pada kelompok perlakuan, tidak ditemukan responden yang menyelesaikan kala II pada kurun waktu 60 - 90 menit, sedangkan pada kelompok kontrol ada $5 \%$ yang menyelesaikan kala II pada rentang ini (Gambar 2).

Jumlah perdarahan pada kelompok perlakuan pada 80 responden berkisar antara 100 sampai dengan 200 mililiter. Sedangkan, pada kelompok kontrol 70\% jumlah perdarahan berkisar antara 200 sampai dengan 300 mililiter (Gambar 3).

Data diuiji normalitasnya mengounakan Shapiro Wilk Test Sebagian besar data menưfiukan distribusi yang tidast normal. Pada kelompok perlakuan distribusi data tingkat nyeri, lama kala II dan jumlah perdarahan menunjukkan sebaran data yang tidak normal. Sedangkan pada kelompok kontrol pada data tingkat nyeri dan lama kala II menunjukkan distribusi data normal tetapi pada data jumlah perdarahan distribusi menunjukkan ketidaknormalan.

Hasil uji pengaruh pijat punggung terhadap pengurangan nyeri persalinan yang dibandingkan dengan hasilnya dengan kelompok yang diberikan perlakuan teknik napas dalam dapat dilihat pada Tabel 1.

Berdasarkan hasil pengolahan data, diketahui pijat punggung memiliki mean 4,55 sedangkan kelompok yang menggunakan teknik napas dalam memiliki rata-rata 6,05. Nilai t hitung 4,88 dan nilai p sebesar 0,0001, maka Ha gagal ditolak sehingga ada pengaruh pijat punggung terhadap penurunan nyeri persalinan fase aktif pada primigravida. Pada hasil uji statistik dengan dengan CI $95 \%$, dapat diketahui bahwa terdapat perbedaan tingkat skala nyeri persalinan. Dapat diketahui bahwa terdapat pengaruh pijat punggung terhadap nyeri kala I pada persalinan primipara (Tabel 1). Responden yang diberi pijat punggung merasakan nyeri persalinan pada tingkatan yang lebih rendah atau dapat diadaptasi dengan baik, dibandingkan apabila tidak diberikan pijat.

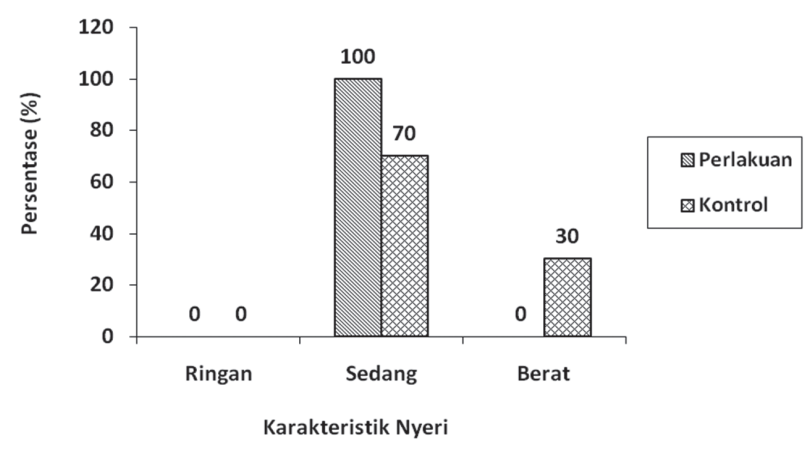

Gambar 1. Persentase Tingkat Nyeri Responden

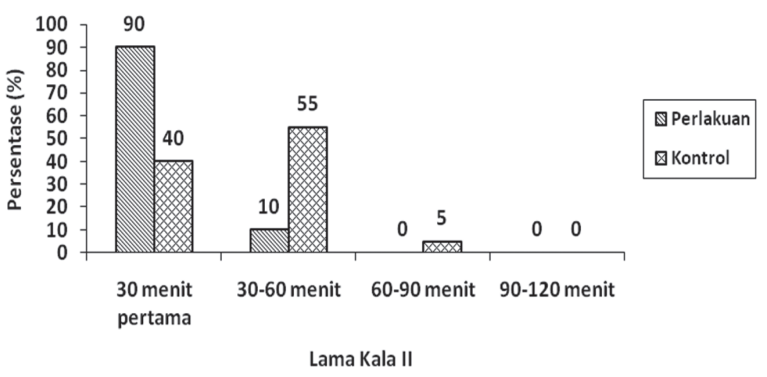

Gambar 2. Persentase Lama Kala II Responden

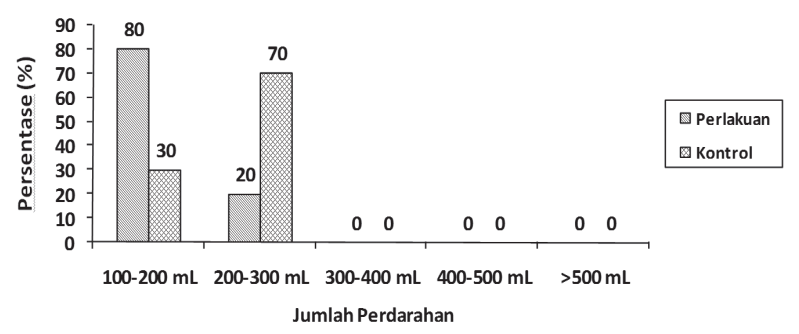

Gambar 3. Persentase Jumlah Perdarahan Persalinan Kelompok Perlakuan Responden 
Tabel 1. Perbedaan Tingkat Nyeri Persalinan pada Primigravida Inpartu Kala I

\begin{tabular}{lcccc}
\hline Perlakuan & Mean & t & Nilai p & 95\% CI \\
\hline $\begin{array}{l}\text { Pijat punggung } \\
\text { Teknik napas dalam }\end{array}$ & 4,55 & 4,88 & 0,0001 & $0,878-2,122$ \\
& 6,05 & & & \\
\hline
\end{tabular}

Tabel 2. Perbedaan Lama Kala II Persalinan pada Primigravida Inpartu Kala I

\begin{tabular}{lcccc}
\hline Perlakuan & Mean & t & Nilai p & 95\% CI \\
\hline $\begin{array}{l}\text { Pijat punggung } \\
\text { Teknik napas dalam }\end{array}$ & $\begin{array}{l}16,85 \\
40,50\end{array}$ & 5,175 & 0,0001 & $14,39-32,90$ \\
\hline
\end{tabular}

Tabel 3. Perbedaan Perdarahan Persalinan Pada Primigravida Inpartu Kala I

\begin{tabular}{lcccc}
\hline Perlakuan & Mean & t & Nilai p & 95\% CI \\
\hline Pijat punggung & 177,50 & 5,177 & 0,0001 & $45,673-104,327$ \\
Teknik napas dalam & 252,50 & & & \\
\hline
\end{tabular}

Berdasarkan hasil uji, diketahui bahwa pijat punggung memiliki rata-rata 16,85 sedangkan kelompok yang menggunakan teknik nafas dalam memiliki rata-rata 40,50. Nilai t hitung 5,175 dan nilai p sebesar 0,0001 maka Ha gagal ditolak sehingga ada pengaruh pijat punggung terhadap lama kala II pada primigravida. Pada hasil uji statistik dengan dengan CI 95\%, dapat diketahui bahwa terdapat perbedaan tingkat lama kala II persalinan. Dapat diketahui bahwa terdapat pengaruh pijat punggung terhadap lama kala II pada persalinan primipara (Tabel 2). Pijat punggung dapat memberikan dampak positif pada ibu yang melahirkan dengan mempercepat waktu pengeluaran bayi atau mempercepat kala II.

Berdasarkan hasil uji, diketahui bahwa pijat punggung memiliki rata-rata 177,50 sedangkan kelompok yang menggunakan teknik napas dalam memiliki mean 252,50 . Nilai t hitung 5,177 dan nilai p sebesar 0,0001, maka Ha gagal ditolak sehingga ada pengaruh pijat punggung terhadap perdarahan persalinan pada primigravida. Pada hasil uji statistik dengan CI 95\%, dapat diketahui bahwa terdapat perbedaan jumlah perdarahan persalinan sehingga dapat diketahui ada pengaruh pijat punggung terhadap jumlah perdarahan pada persalinan primipara (Tabel 3). Pijat punggung dapat menyebabkan pengeluaraan darah persalinan yang lebih sedikit dibandingkan bila ibu bersalin tidak diberi pijat.

\section{Pembahasan}

Berdasarkan data tingkat nyeri pada kelompok perlakuan dan kelompok kontrol ada perbedaan, yaitu pada kelompok perlakuan dengan diberikan pijat punggung $100 \%$ berada pada tingkat nyeri sedang. Pada kelompok kontrol $70 \%$ mengalami nyeri pada tingkat sedang dan $30 \%$ pada tingkat berat. Hasil ini senada dengan nilai uji beda yang menunjukkan ada beda pada tingkat nyeri antara kelompok yang mendapat perlakuan dengan kelompok kontrol. Nyeri merupakan mekanisme fisiologis yang bertujuan untuk melindungi diri. Apabila seseorang merasakan nyeri maka perilakunya pun berubah. Ibu yang akan melahirkan harus mampu beradaptasi dengan nyeri. Jika ibu tidak mampu beradaptasi, akan mengakibatkan kecemasan dan kelemahan fisik akibat respons yang berlebihan terhadap nyeri yang dirasakan. ${ }^{10}$ Nyeri persalinan juga dapat menyebabkan timbulnya hiperventilasi sehingga kebutuhan oksigen meningkat, motilitas usus serta vesika urinaria. Keadaan ini akan merangsang peningkatan ketokolamin yang dapat menyebabkan gangguan pada kekuatan kontraksi uterus sehingga terjadi inersia uterus yang dapat berakibat kematian ibu saat melahirkan. ${ }^{11}$

Nyeri yang dirasakan ibu melahirkan terjadi karena adanya mekanisme persalinan. Impuls saraf, yang dihasilkan oleh stimulus nyeri, menyebar di sepanjang serabut saraf perifer aferen. Transmisi stimulus nyeri berlanjut di sepanjang serabut saraf aferen sampai transmisi tersebut berakhir di bagian kornu dorsalis medulla spinalis. Di dalam kornu dorsalis, neurotransmitter, seperti substansi P dilepaskan sehingga menyebabkan suatu transmisi sinapsis dari saraf perifer (sensori) ke saraf traktus spinotalamus. ${ }^{10} \mathrm{Hal}$ ini memungkinkan impuls nyeri ditransmisikan lebih jauh ke dalam sistem saraf pusat. Stimulus nyeri berjalan melalui serabut saraf di traktus spinotalamus yang menyeberangi sisi yang berlawanan dengan medulla spinalis. Impuls nyeri kemudian berjalan ke arah medulla spinalis. Setelah impuls nyeri naik ke medulla spinalis, maka informasi ditransmisikan dengan cepat ke pusat yang lebih tinggi di otak, termasuk pembentukan retikular, sistem limbik, talamus, korteks sensori, dan korteks asosiasi.

Teori pengontrol nyeri, impuls nyeri dapat diatur atau bahkan dihambat oleh mekanisme pertahanan di sepanjang sistem saraf pusat. Mekanisme pertahanan dapat ditemukan di sel-sel gelantinosa substansia di dalam kornu dorsalis pada medulla spinalis, talamus, dan sistem limbik. Teori ini mengatakan bahwa impuls nyeri dihantarkan saat sebuah pertahanan dibuka dan impuls dihambat saat sebuah pertahanan tertutup. Upaya menutup pertahanan tersebut merupakan dasar terapi menghilangkan nyeri. ${ }^{10}$ Pijat punggung diduga dapat menurunkan persepsi nyeri dengan menstimulasi sistem kontrol desenden, sehingga lebih sedikit stimuli nyeri yang ditransmisikan ke otak. Jika impuls nyeri dihantar ke otak, terdapat pusat korteks yang lebih tinggi di otak yang memodifikasi persepsi nyeri di mana alur saraf desenden akan melepaskan opiate endogen, seperti endorfin dan dinorfin, yaitu suatu pembunuh nyeri alami yang berasal dari tubuh. Neuromodulator ini menutup mekanisme pertahanan dengan menghambat pelepasan substansi. ${ }^{12}$

Pijat punggung bekerja memberikan pengaruh paling 
baik untuk jangka waktu yang singkat, untuk mengatasi nyeri intensif hanya berlangsung beberapa menit, misalnya selama pelaksanaan prosedur invasif atau saat menunggu persalinan. ${ }^{10}$ Pemakaian teknik pijat punggung pada ibu primigravida inpartu kala I ini dapat membantu menurunkan skala nyeri yang dirasakan ibu primigravida, dengan teknik ini ibu primigravida akan lebih rileks dan santai sehingga akan mengurangi ketegangan karena dilepaskannya endorfin yang dapat membantu mengurangi skala nyeri pasien. Selain itu, perasaan santai dan tenang dapat mengubah tingkat oksidasi monoamine yang metabolisme serotonine. Padahal, serotonine adalah zat kimia yang bisa menghilangkan rasa sakit. Dengan kata lain, relaksasi dan sentuhan bisa membantu menghilangkan rasa sakit.

Pernapasan yang dalam juga bisa memberikan efek relaksasi pada ibu yang mengalami nyeri persalinan. Ibu bersalin diajari teknik bernapas dalam. Setelah mampu melakukan, ibu dibiasakan untuk bernapas dalam setiap nyeri timbul secara mandiri. ${ }^{4}$ Berbeda dengan teknik pijat, ibu bersalin akan selalu mendapat sentuhan ataupun perhatian dari pendamping persalinan yang memberikan pijat. Sebagaimana diketahui salah satu faktor yang memengaruhi nyeri adalah dukungan sosial dan keluarga sehingga ibu bersalin dapat beradaptasi terhadap nyeri dengan lebih baik. ${ }^{10}$ Rasa nyeri pada persalinan dalam hal ini adalah nyeri kontraksi uterus yang dapat mengakibatkan peningkatan aktivitas sistem saraf simpatis, perubahan tekanan darah, denyut jantung, pernapasan dengan warna kulit dan apabila tidak segera ditangani akan meningkatkan rasa khawatir, tegang, takut, dan stres. ${ }^{4}$ Rasa takut dan sakit juga menimbulkan stres yang mengakibatkan pengeluaran adrenalin. Hal ini mengakibatkan penyempitan pembuluh darah dan mengurangi aliran darah yang membawa oksigen ke rahim sehingga terjadi penurunan kontraksi rahim yang akan menyebabkan memanjangnya waktu persalinan.

Berdasarkan data yang didapatkan, 90\% responden yang mendapat perlakuan pijat punggung bisa melahirkan bayi pada 30 menit pertama setelah dinyatakan pembukaan lengkap. Pada kelompok kontrol, hanya 40\% yang melahirkan pada 30 menit pertama. Dari hasil uji statistik, didapatkan hasil $p<0,05$ sehingga ada pengaruh pijat punggung terhadap lama kala II pada persalinan. Pada penelitian ini, pijat punggung secara statistik bisa membantu ibu beradaptasi dengan nyeri. Ketika ibu sudah merasa tenang dan rileks, rasa takut yang muncul dapat teratasi sehingga pengeluaran adrenalin yang berlebih dapat diantisipasi, zat-zat penghambat rangsang nyeri pun dapat disekresikan dengan baik. Dengan berkurangnya adrenalin, pembuluh darah dapat bervasodilatasi dengan baik, sehingga dapat memperlancar aliran darah yang membawa oksigen ke rahim. Ketika oksigen dalam rahim tercukupi, kontraksi dapat berjalan dengan baik sehingga ibu mampu meneran dengan maksimal yang akan mengakibatkan kelancaran pada persalinan khususnya kala II.

Penelitian Sheiner dan Sarid, ${ }^{13}$ menjelaskan dalam sebuah persalinan pada individu yang paling berisiko mengalami perdarahan postpartum segera setelah melahirkan adalah wanita dengan hipertensi kehamilan yang diinduksi, wanita yang mengalami kala II lama atau yang berkepanjangan, wanita yang diinduksi atau dipacu persalinannya, wanita yang bayinya dilahirkan melalui ekstraksi vakum, wanita dengan bayi yang besar atau lebih besar dari usia kehamilannya.

Kecemasan dapat meningkatkan denyut jantung dan penurunan imunitas. Kecemasan menyebabkan migrasi trombosit ke daerah perifer sehingga pembekuan darah memendek dan terjadi juga peningkatan perfusi yang akan membahayakan saat terjadinya pemutusan pembuluh darah yakni meningkatkan risiko terjadinya perdarahan. ${ }^{14}$ Sedangkan penelitian Handayani, ${ }^{7}$ didapatkan hasil sebagian responden sebelum dilakukan pijat punggung mengalami nyeri tingkat berat $(51,4 \%)$, nyeri sedang $(42,9 \%)$ dan nyeri ringan $(5,7 \%)$ setelah dilakukan pijat ibu yang mengalami nyeri sedang $(57,2 \%)$ nyeri ringan $(25,7 \%)$ dan hanya $(17,1 \%)$ yang mengalami nyeri berat. Adapun yang membedakan dengan penelitian ini adalah adanya kelompok kontrol serta penambahan variabel terikat yaitu lama persalinan dan jumlah perdarahan.

Pada penelitian ini, responden yang mendapatkan pijat punggung mampu beradaptasi dengan nyeri. Responden mampu untuk menjalani persalinan lebih rileks dengan kecemasan yang minimal karena mampu merespons secara adaptif terhadap nyeri. Responden juga menempuh waktu untuk kala II yang lebih pendek dibandingkan kelompok kontrol. Data yang peneliti dapatkan pada variabel perdarahan persalinan 80 responden berkisar antara 100 sampai dengan 200 mililiter. Sedangkan pada kelompok kontrol 70 persen jumlah perdarahan berkisar antara 200 sampai dengan 300 mililiter. Hasil uji statistik menunjukan nilai yang signifikan dimana ada pengaruh pijat punggung terhadap jumlah perdarahan.

Perdarahan persalinan merupakan komplikasi dari kala II lama, akibat uterus yang mengalami kelelahan. ${ }^{13}$ Selain itu, perdarahan juga bisa terjadi pada wanita yang mengalami kecemasan maupun stres dalam persalinannya yang terjadi karena rasa nyeri pada saat kontraksi persalinan. Menurut ilmu psikoneurologi, kecemasan dapat meningkatkan denyut jantung dan penurunan imunitas. Kecemasan menyebabkan migrasi sel trombosit ke darah perifer sehingga pembekuan darah memendek dan terjadi juga peningkatan perfusi yang akan membahayakan saat terjadi pemutusan pembuluh darah yakni meningkatkan risiko perdarahan. ${ }^{14}$ Beberapa kegiatan yang dapat dilakukan untuk mencegah terjadinya perdarahan adalah dengan memberikan kenyamanan pada 
ibu yang mau melahirkan dan berupaya agar kala II tidak lama. Melihat hasil penelitian ini, klien yang diberikan pijat punggung akan mendapatkan manfaat berlipat. Dengan dipijat, nyeri klien dapat terkontrol sehingga kecemasan klien dapat berkurang, kala II menjadi lebih cepat dan risiko perdarahan dapat diminimalkan. Penetapan responden yang peneliti lakukan masih memungkinkan adanya bias pada hasil penelitian. Seharusnya peneliti memasukkan kriteria pendamping responden dalam proses persalinan. Dalam penelitian ini, peneliti belum memasukkan kriteria tersebut.

\section{Kesimpulan}

Setelah data dari penelitian yang dilaksanakan di Puskesmas Magelang Selatan dianalisis, dapat disimpulkan bahwa pijat punggung memberikan pengaruh yang baik terhadap adaptasi nyeri persalinan. Wanita yang bisa beradaptasi dengan nyeri persalinan dapat lebih mudah menjalani proses persalinan terutama pada kala II sehingga proses pengeluaran bayi bisa lebih cepat dan menghilangkan kecemasan yang dapat memengaruhi perfusi jaringan.

\section{Saran}

Bagi rekan sejawat perawat/bidan penolong persalinan hendaknya selalu melaksanakan teknik pijat punggung untuk mengurangi rasa nyeri persalinan dan mengajarkan kepada keluarga/pendamping. Untuk keluarga/pendamping persalinan, agar dapat berpartisipasi dalam melakukan pijat punggung pada ibu bersalin untuk mengurangi rasa nyeri, memperpendek lama kala II dan mengurangi jumlah perdarahan. Untuk Puskesmas Magelang Selatan, disarankan untuk mengajarkan upaya untuk mengurangi nyeri persalinan, lama kala II dan jumlah perdarahan dengan teknik pijat punggung ibu sejak klien masih hamil dan perlu diadakan prenatal class sebagai sarana transfer pengetahuan. Untuk peneliti selanjutnya, hendaknya melakukan penelitian secara berke- lanjutan dengan menganalisis faktor-faktor lain yang berpengaruh terhadap persalinan (misalnya, pengalaman nyeri sebelumnya, penyakit fisik yang menyertai, latar belakang budaya dan tempat tinggal).

\section{Daftar Pustaka}

1. Wiknjosastro H. Ilmu kebidanan. Jakarta: Yayasan Bina Pustaka Sarwono Prawirohardjo; 2005.

2. Danuatmaja B, Mila. Persalinan normal tanpa rasa sakit. Jakarta: Puspa Swara; 2004.

3. Mander, R. Nyeri persalinan. Jakarta: EGC; 2004.

4. Bobak IM. Buku ajar keperawatan maternitas. Jakarta: EGC; 2005.

5. Arikunto S. Prosedur penelitian suatu pendekatan praktik. Jakarta: Rineka Cipta; 2006.

6. Sugiyono. Statistika untuk penelitian. Bandung: CV Alvabeta; 2007.

7. Handayani E, Girikisyowo P. Pengaruh massage punggung terhadap penurunan nyeri fase aktif pada ibu bersalin. Jurnal Kebidanan. 2012; 4 (2): $57-8$

8. Budiarto E. Biostatistika untuk kedokteran dan kesehatan masyarakat. Jakarta: EGC; 2001.

9. Notoatmodjo S. Metodologi penelitian kesehatan. Jakarta: Rineka Cipta; 2002.

10. Potter PA, Perry AG. Buku ajar fundamental keperawatan: konsep, proses, praktik. Jakarta: EGC; 2006.

11. Azizah IN, Widyawati MN, Anggraeni NN. Pengaruh endorphin massase terhadap intensitas nyeri kala I persalinan normal ibu primipara di BPS S dan B Demak Tahun 2011. Jurnal Unimus [online]. 2011 [diakses tanggal 6 Februari 2013]; 6. Diunduh dalam: http://jurnal unimus.ac.id.p91.

12. Smeltzer SC, Bare GB. Buku ajar keperawatan medikal bedah. Jakarta: EGC; 2008.

13. Sheiner E, Sarid L, Levy A, Seidman DS, Hallak M. Obstetric risk factors and outcome of pregnancies complicated with early postpartum hemorrhage: a population-based study. Journal of Maternal Fetal and Neonatal Medicine. 2005 Sept; 18 (3); 149-54.

14. Kiecolt-Glaser JK, McGuire L, Robles T, Glaser R. Psychoneuroimmunology: psychological influences on immune function and health. Journal of Consulting and Clinical Psychology. 2002; 70: 537-47. 